\title{
PROSPECTS FOR THE FUTURE OF COMMERCIAL PRINTING
}

\author{
Csaba Horváth ${ }^{1}$ (D), László Koltai ${ }^{1}$ (iD), Klaudia Maňúrová ${ }^{2}$ (iD \\ ${ }^{1}$ Óbuda University, Institute of Media Technology \\ and Light Industry Engineering, Budapest, Hungary \\ ${ }^{2}$ University of Sopron, József Cziráki Doctoral School \\ of Wood Sciences and Technologies, Sopron, Hungary
}

\begin{abstract}
The rate of change for the commercial printing industry with regard to technology, business models and customer demand is growing, and the landscape of the industry already looks vastly different from a few short decades ago. Across the commercial print sector today, there are many different types of companies - some very successful, with a young, skilled, enthusiastic workforce who have no trouble innovating and recruiting. However, as in any rapidly developing sector, other companies are trailing behind.

Demographic changes are entering the market (Generation Z), as well as the upper levels of management in printing companies (Millennials), and "their preferences are now their demands". This requires business models to be re-invented and a more intensive focus on issues relating to sustainability.

The authors of the article summarize the future of the world of commercial printing and the current state of European commercial printing. They have based their work on a report published by the Smithers Research Institute in January 2020 on this topic and on the professional findings and arguments presented at major scientific conferences over the past two years, with the aim of getting these latest ideas to the earliest helping the researchers and practitioners to adapt to the rapidly changing situation and the challenge.
\end{abstract}

Key words: commercial printing, the future of commercial printing, new business model, sustainability, printing technologies

\section{INTRODUCTION AND METHODOLOGY}

The rate of change for the commercial printing industry with regard to technology, business models and customer demand is growing, and the landscape of the industry already looks vastly different from a few short decades ago. The authors of the article summarize the future of the world of commercial printing and the current state of European commercial printing. They have based their work on a report published by the Smithers Research Institute in January 2020 on this topic and on the professional findings and arguments presented at major scientific conferences over the past three years, with the aim of getting these latest ideas to the earliest helping practitioners to adapt to the rapidly changing situation and the challenges.

The conferences are as follows:

- $\quad$ Print Matters for the Future: PRINT 4.0 - The annual conference of INTERGRAF (European Federation of for Print and Digital Communication), Milano, Italy, June 1, 2018

- TAGA 2019 - The Annual Conference of the Technical Association of the Graphic Arts, Minneapolis, USA, March 16-19, 2019;

- $\quad$ Print Matters for the Future - The annual conference of INTEGRAF, London, UK, May 24, 2019

- $\quad$ IARIGAI 2019 - 46 $6^{\text {th }}$ International Research Conference of IARIGAI (International Association of Research Organization for the Information, Media and Graphic Arts Industries), Stuttgart, Germany, September 15-18, 2019;

- Shaping the Future of Print: Commercial Print 2020 - International conference of INTERGRAF, Brussels, Belgium, February 21, 2020

\section{COMMERCIAL PRINT}

What is the commercial print? it encompasses a broad range of printed items, generally undertaken on a print-for-pay basis, and excludes home/office/workgroup printing. The commercial print covers the a wide-range of informational, promotional and advertising printed items, such as photobooks, indoor/outdoor signage, brochures/leaflets, envelopes, business cards/stationary, direct mail, vinyl record 
sleeves, display products and much more. It mostly excludes books, directories, newspapers, magazines, labels, packaging, various functional \& industrial and textile printing.

Broadly speaking, commercial print encompasses informational, promotional and advertising print, mostly undertaken on paper, and includes the following.

- Direct mail - addressed advertising mail: printed envelopes, sales letters, packets (nonpersonalised coupon books), self-mailers (include reply address in single piece), reply cards, postcards, advertising mail flyers \& notices, others; unaddressed advertising mail items (similar items to direct mail including door drops);

- Inserts - newspaper inserts, magazine inserts excluding coupon books;

- Brochures \& pamphlets (excluding financial publications, etc.), other promotional print brochures (sales), leaflets, flyers \& notices, price lists, datasheets (technical, etc.), booklets, folders, other promotional print;

- Indoor point-of-sale materials/signage

posters, other temporary point-of-sale materials, counter \& floor displays, large-format point-ofpurchase materials, corporate graphics, exhibition \& trade show materials, fine art reproduction, photo-printing;

- $\quad$ Outdoor point-of-sale materials/signage -billboards, banners, flags \& backdrops, vehicle/ fleet graphics, building wraps/other graphics, decals (transfers), sails, hot air balloons, marquees, etc.;

- Catalogues - sales catalogues, mail order catalogues, magalogues;

- Business forms - manifold business forms;

- Business ID - letterheads, compliment slips, business cards, printed envelopes and quotes/ invoices;

- Financial \& legal printing - annual reports \& other earnings releases, company brochures, prospectuses, etc.;

- Coupons, tickets \& tapes;

- Manuals - user guides (technical communication document) giving assistance to people using a particular system. This only includes manuals given away with products and excludes manuals sold separately;

- Newsletters - printed report containing news concerning the activities of a business or an organisation that is sent to its members, customers, employees or other subscribers;

- Transactional print - bills, statements, etc.;

- Security printing - cheques (unless shown separately), personal ID (passports, driving licenses, etc.), credit/debit cards, banknotes, secure documents, etc.;

- $\quad$ Others - includes non-categorised products, as well as other one-off jobbing work that will be a significant part of the market and also a certain amount of photo printing carried out by quick printers and others. Non-categorised products include scientific/technical recording chart/chart paper printing, maps and similar, calendar/calendar pads, playing cards, decalcomanias (transfers), art reproduction, postcards, certificates, games, customised gifts, greeting cards, etc. It also includes some 'informational print', leaflets and similar printed items often used in public sector/ similar institutions. There is wrapping paper and the scope extends to printed beer mats and even printed napkins and branded table mats.

\section{MARKET OVERVIEW: THE COMMERCIAL PRINTING IN EUROPE}

The commercial printing industry in Europe has in recent years been encountering significant challenges as a result of declines in graphic printing demand across a range of areas. Advertising print has been hit by the growth in online advertising

and also, the growth in electronic screens used in outdoor advertising locations. Similar declines have been seen elsewhere, as products like business forms, annual reports and other traditional printed items have switched largely away from print to digital. The impact of this has been seen in the declines in the numbers of companies operating in Europe's printing and allied industries, projected to fall by around 13\% between 2014 and the end of the current year, 2020. It should be noted, however, that commercial printing establishments - as defined by Eurostat and other statistical offices - do not represent the whole picture. Many companies engaged in printing activities often do not self-define officially as printers.

These include some or all of the following. 
- Direct mail publishing houses

- Signage companies

- In-plants (reprographics)

- Print management companies

- Designers and agencies

- Marketing service providers

- High-street print shops

- Mailing houses

- Speciality print finishers

There may be other players producing commercial print products, and catalogues.

The largest individual elements in value terms tend to be major advertising segments such as PoS/signage, brochures/other promotional print, direct mail and catalogues, with significant revenues also accounted for by transactional print, financial \& legal printing and other areas. 'Others' shown in figure 1 includes a variety of one-off jobbing print that is often difficult to categorize, and could sometimes be reallocated to defined segments.

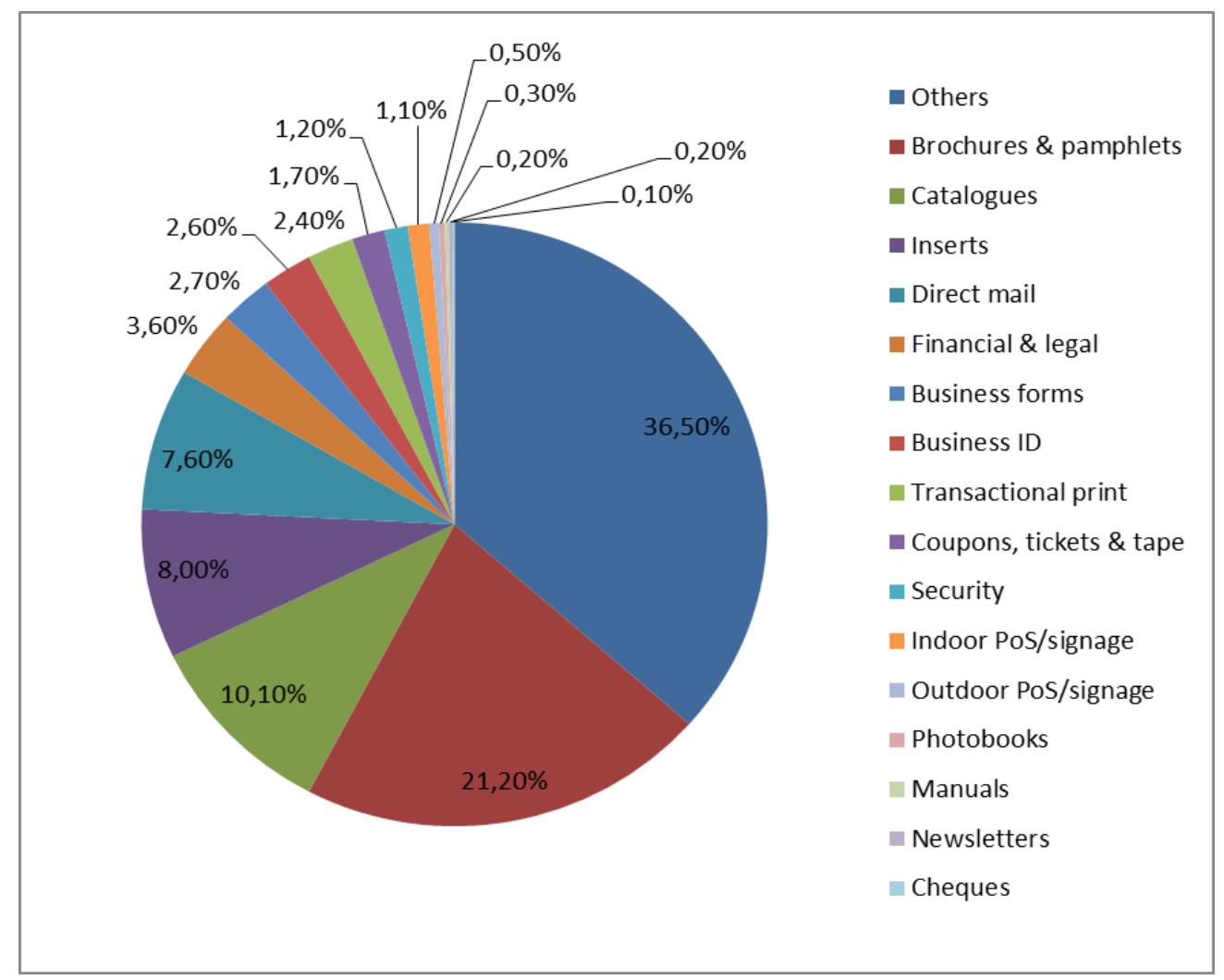

Figure 1: European commercial printing output by print product, 2020 (share by volume, A4 prints or equivalent) (Smyth, 2020)

In volume terms, the splits are similar although higher-priced areas such as PoS/signage take a smaller share, mainly down to the short runs employed and high level of digital penetration that tend to push prices up.

Almost all commercial printing segments have been in decline in both volume and value terms in recent years, and are forecast to develop along the same lines broadly going forward (Hawkins, 2018). Where there is growth in value, this tends to be focused on those areas where digital print has made some inroads, and this also often translates into A4 volume growth in those areas where digital overprinting is undertaken - however, because overprinting counts as two, this also means that the final printed is not necessarily increasing. 


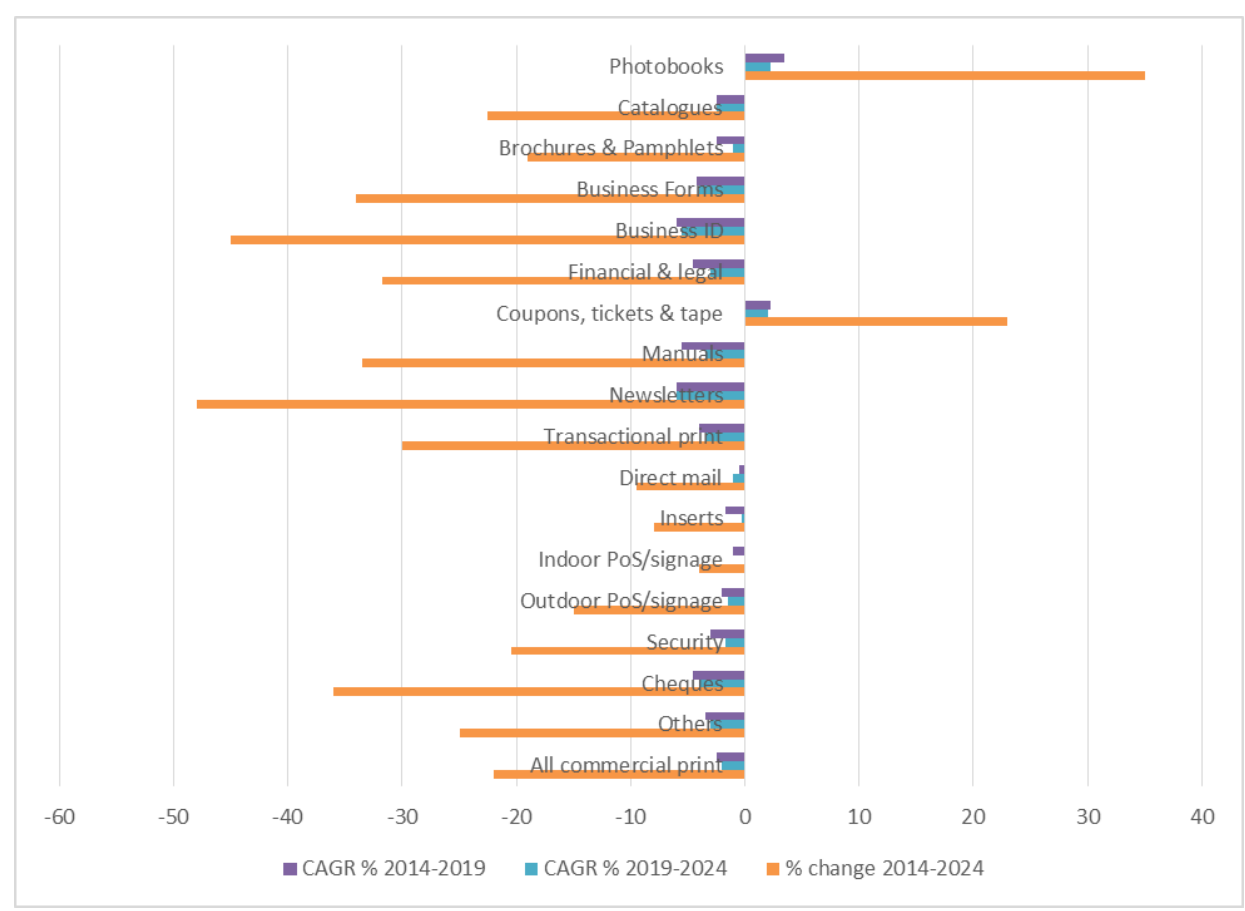

Figure 2: Trends in European commercial printing ouzput by print product, 2014-2024 (billion A4 prints or equivalent) (Smyth, 2020)

One key area that has been hit by the switch to digital alternatives has been catalogues. Catalogue printing has declined rapidly as retailers have switched to a large extent to online sales channels that offer a quicker, more dynamic means to advertise, promote and sell a company's products. There has been growth in more targeted 'magalogues' (magazine+catalogues), although this has not prevented an overall decline in printing output, from 353 billion A4 prints or equivalent in 2014 valued at €4.05 billion at constant 2018 prices \& exchange rates to 310 billion A4 prints (€3.32 billion) by 2019.

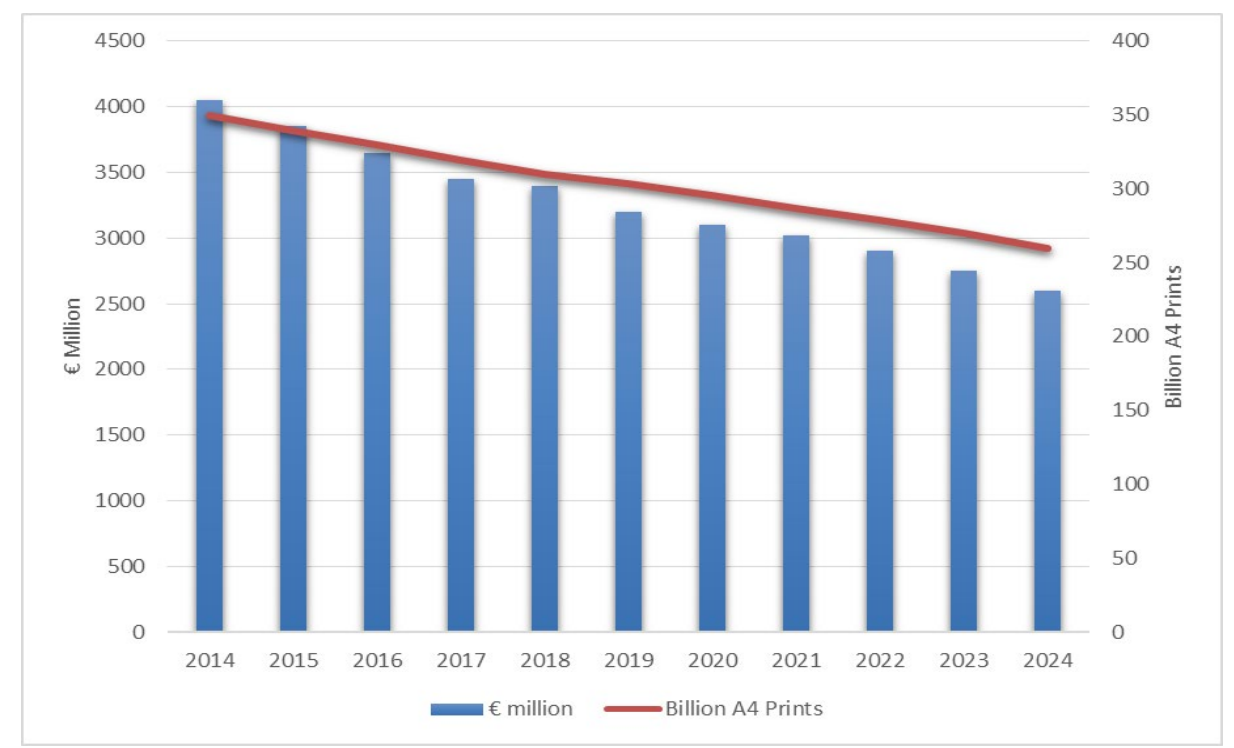

Figure 3: European catalogue printing output, 2014-2024

(€ million, constant 2018 prices c exchange rates; billion A4 prints or equivalent) (Smithers, 2020)

\section{COMMERCIAL PRINTING TECHNOLOGY TRENDS}

Commercial printing is dominated by sheetfed offset litho and digital, with inkjet growing beyond the key mailing \& display areas into broader areas of commercial print. The share of digital in 2019 stood at $10 \%$ 
in volume terms vs $41 \%$ in value terms, up from $8 \%$ and $31 \%$ respectively in 2014 and forecast to rise to $14 \%$ and $49 \%$ respectively by 2024 .

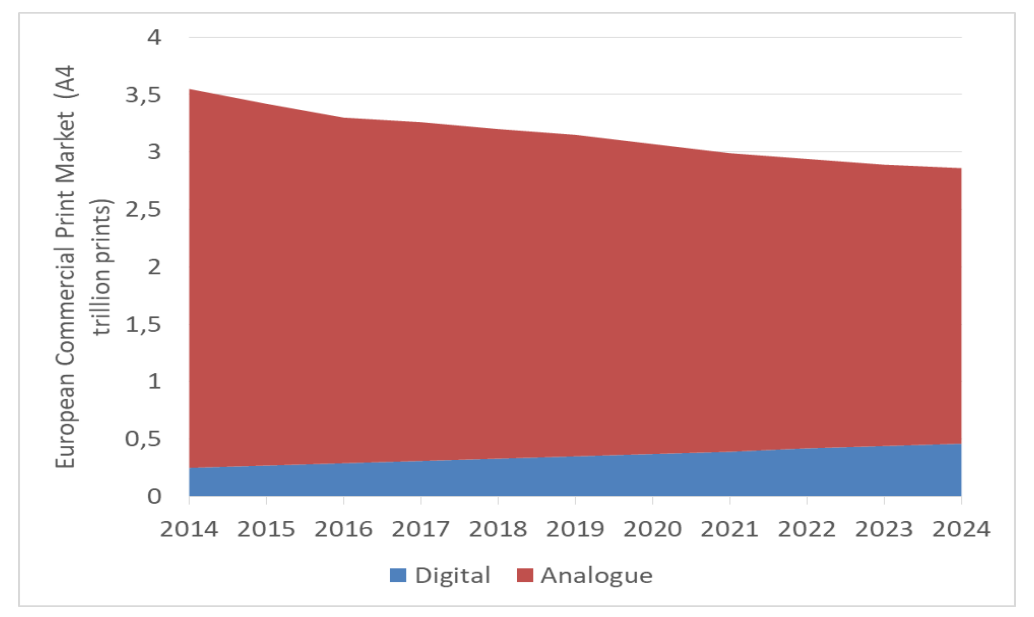

Figure 4: Commercial Print Technology Dominated by sheetfed litho (offset) and digital (inkjet growing beyond mailing \& display into commercial) (Smyth, 2020)

Although digital is expected to make further inroads during the coming years, there are a number of trends that have contributed towards improvements in business efficiencies and profitability in the sheetfed offset litho arena incorporating increasing automation (push-to-stop) and standardisation, as well as growing use of UV to speed turnround. Productivity has been boosted through the implementation of lean processes, with rising adoption of web-to-print leading to the ganging-together of standard jobs to share make-readies and lower cost. In electrophotography, much of the focus today has been in improvements in print quality and also moves towards larger format print, with step changes in productivity and cost being seen in the current year. In inkjet, meanwhile, print quality improvement is also a few focus, including on standard papers, wide format, webfed (new finishing solutions) and sheetfed presses (Mellor, 2019; Politis et al, 2019). Digital finishing and embellishment is also growing across the board.

A number of new inkjet machines are set for launch at DRUPA in 2020 (now 2021). Improvements in productivity, speed and quality are set to open up new areas for inkjet, not only in commercial printing areas including promotional and informational print, but also in areas like packaging, décor, and textiles and promotional objects (Mechling, 2019).

There is much interest in key Landa installations, with its sheetfed and web nanographic printing presses said to offer the versatility of digital printing with the qualities and speed associated with offset, employing water-based inks and a novel image transfer system. The ink image is converted into a very thin polymeric film on a hot blanket, which is then transferred onto the cool paper surface. This is claimed to avoid any issues of paper saturation that can be associated with conventional inkjet processes, and to provide high-quality images at high print speeds. In Europe, Landa machines are being used or about to be installed in four plants in Germany, the UK, France and the Netherlands, as well as at several packaging providers. Early adopters report the Landa technology is highly competitive in the range of 250-500 sheets against litho and other digital processes (Martowidjojo, 2018).

\section{CHANGING BUSINESS MODELS - THE RISE OF WEB-TO-PRINT}

Business models are changing in a variety of business sectors, and these changes are finding their way to a greater or lesser degree into the commercial printing industry. User expectations are changing, and moves towards just-in-time delivery and fast turnround across the board are being shadowed in commercial printing through the use of appropriate workflow solutions. Next day are even same day delivery are becoming more common, with printers seeking to serve the increasingly demanding customer - more quickly, more sustainably, more cheaply, more relevantly and with less or no stock to burden them. Workflow, from customer enquiry to delivery, is critical for commercial print businesses to be successful as run lengths fall while customers expect ever faster delivery. 
A key change has been in the role of commercial printing companies at the cutting edge, many of which now has reduced direct relations with their customers but instead deal mainly or in some exclusively with resellers, and focus entirely on building the most efficient printing business, in part through the adoption of on-line ordering, web-to-print. This has opened the market for individual consumers and micro businesses, to create small quantities of promotional and marketing collateral at affordable costs (Martowidjojo, 2018; Zipper, 2019).

This is mirroring trends elsewhere, as companies have been finding ways of creating value for themselves, their suppliers, converters and users, by developing a new layer that integrates them all with maximum utility. 'Uberisation' is developing in many industries, where the focus is on the customer and not the manufacturing.

The key is to own the relation with the buyer, not the manufacturing capability or service provision. It is happened in printing as commercial printers develop workflow solutions that automate artwork production and administration (Karlovits, 2019). Some printers have succeeded in trapping the series of processes - design, materials, suppliers, production and distribution - into an on-demand appaccessible service. This has led to a new way to fill presses, and it has revolutionised the sheetfed litho sector in Europe.

Definitions can vary, but fundamentally web-to-print (Web2Print, WTP) is a broad term that covers the eprocurement mechanism of print buying. Orders are placed on a web site or portal, choosing from a catalogue of stock items or specifying and creating the printed material using the online app. Typically, these systems will generate artwork (or allow upload of artwork into a workflow with pre-flight); provide estimates and accept payment (as an order number for established client or through funds transfer for a new customer) as part of the process (Karlovits, 2019). Customers may be businesses or individual consumers. Trade print services are growing strongly - often offering a service branded as the buying organisation. There is no direct sales person involvement; the system handles the transaction completely (Zipper, 2019).

The web-to-print market worldwide was valued at around $€ 22$ billion in 2018 , equating to around some $3.0 \%$ of all print and printed packaging set to rise to $3.6 \%$ by 2023 . There are regional variations, with the highest proportion in Western Europe where $7.2 \%$ of all print was purchased and specified through webto-print in 2018, rising to $8.6 \%$ in 2023 . This is a consequence of the activities of a range of sheetfed litho companies using online printing - in Germany, Austria and Switzerland especially. Web-to-print output grew by around 12\% per annum in Western Europe in value terms between 2013 and 2018, and is set to grow by around 4\% per annum over the period from 2018-2023.

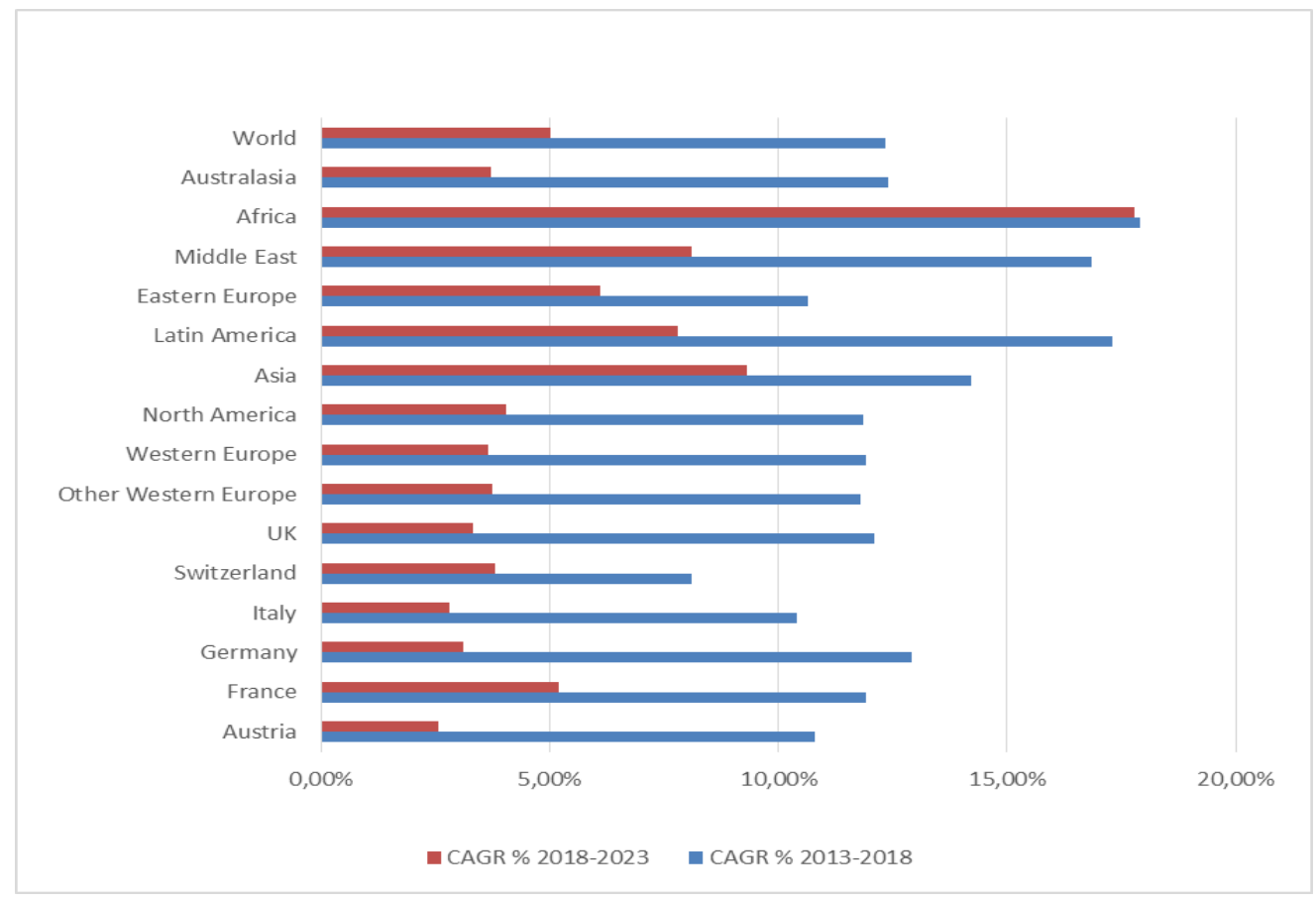

Figure 5: Trends in global web-to-print output by geographic market, 2013-2023 (change in value, constant prices \& exchanges rates) (Smithers, 2020) 
Demographic changes are entering the market (Generation Z), as well as the upper levels of management in printing companies (Millennials), and "their preferences are now their demands". This requires business models to be re-invented and a more intensive focus on issues relating to sustainability. In order to not only survive, but thrive in today's new context printers to think about their customers in a different way and re-invent their business models to better meet customers' - and employees' - changing demands (Gerosa, 2018)

\section{CONCLUSIONS}

The commercial printing sector in Europe as a whole will continue to face major challenges, particularly in line with declining demand for graphic printing volumes with many catalogues and commercial print products no longer existing physically. Further consolidation within the sector seems inevitable, with the number of commercial printers in operation set to fall still further. There will be winners and losers, with new no-touch workflows allowing culture shifts from focusing on being the best ink-on-paper printer into optimizing customer relationships and experiences.

Other companies who succeed in this new decade may adopt a combination of diversification into new products and services on the one hand (e.g. packaging and labels, industrial/object printing, etc.) and into new customer markets on the other.

\section{MANAGE THE RISK!}

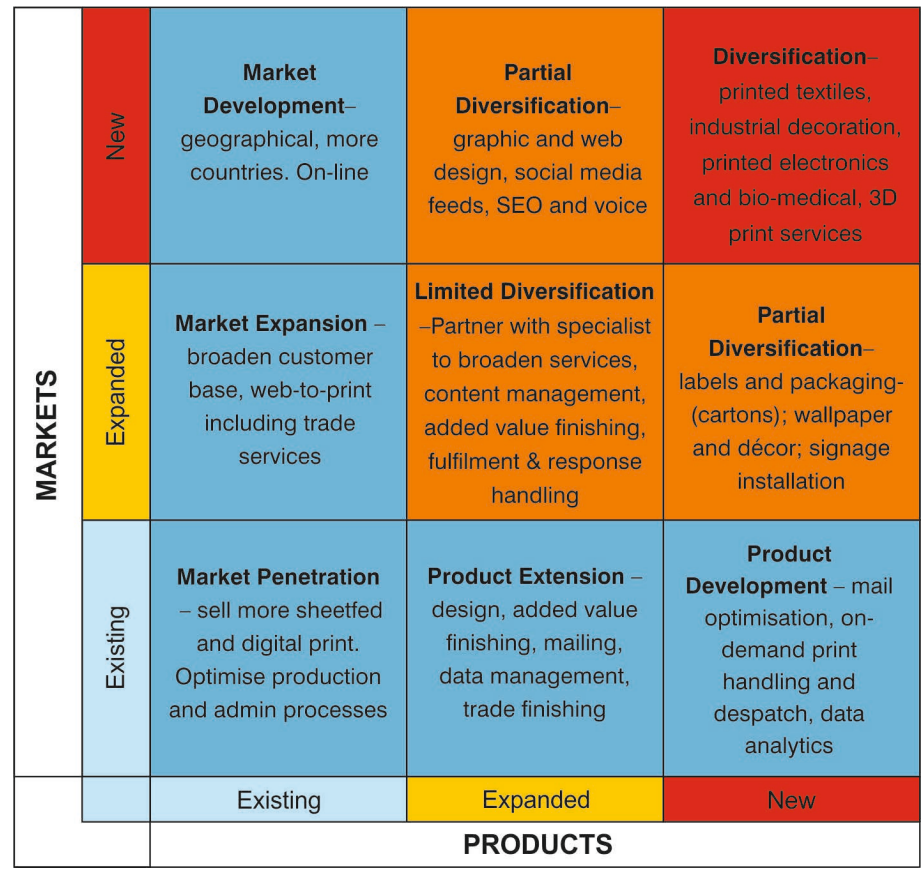

Figure 6: Opportunities for diversification in commercial print (Smithers, 2020)

\section{ACKNOWLEDGMENTS}

The authors thank the INTERGRAF staff (conference organizers) for giving the presentations at the conferences and the Smithers-INTEGRAF Report made available to them.

\section{REFERENCES}

[1] Gerosa, A.: "Think Young (Europe)", Print Matters for the Future 2018, (PRINT 4.0 - The annual conference of INTERGRAF, Milano, Italy, 2018).

[2] Hawkins, F.: "The print paradox", Print Matters for the Future 2018, (PRINT 4.0 - The annual conference of INTERGRAF, Milano, Italy, 2018). 
[3] Karlovits, I.: "Print and Packaging in the world of Big Data, Al and Blockchains", Proceedings of International Joint Conference on Environmental and Light Industry Technologies 2019, (IJCELIT, Budapest, Óbuda University, 2019), pages 8-14.

[4] Martowidjojo, A.: "The Future of print", Print Matters for the Future 2018, (PRINT 4.0 - The annual conference of INTERGRAF, Milano, Italy, 2018).

[5] Mechling, S.: "Digital transformation in the print media industry - how to drive the change?", 46th International Research Conference 2019, (Stuttgart, Germany 2019).

[6] Mellor, G.: "Print trends: a guide to improving operational performance", Print Matters for the Future 2019, (INTEGRAF, London, UK, 2019).

[7] Politis, A., Macro, K., Gamprellis, G., Trochoutsos, C., Tsigonias, M.: "Matching lean manufacturing and industry 4.0 for the graphic communication - printing industry", Proceedings of the $46^{\text {th }}$ International Research Conference of IARIGAI 2019, (IARIGAI, Stuttgart, Germany, 2019), pages 9197.

[8] Smithers, Intergraf: Commercial Print and Catalogues - Market Report, 2020.

[9] Smyth, S.: "Commercial printing futures", International conference of INTERGRAF 2020, (Brussels, Belgium, 2020).

[10] Zipper, B.: “Online print: Intermediate stage to PRINT 2.0 or a revolution?", Print Matters for the Future - The annual conference of INTEGRAF 2019, (London, UK, 2019).

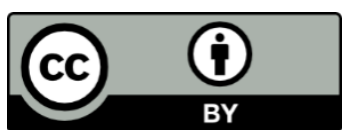

(C) 2020 Authors. Published by the University of Novi Sad, Faculty of Technical Sciences, Department of Graphic Engineering and Design. This article is an open access article distributed under the terms and conditions of the Creative Commons Attribution license 3.0 Serbia (http://creativecommons.org/licenses/by/3.0/rs/). 